\title{
Children's Peer Assessment and Self-disclosure in the Presence of an Educational Robot
}

Conference Paper · August 2016

DOI: 10.1109/ROMAN.2016.7745170

CITATIONS

2

6 authors, including:

\section{Shruti Chandra}

École Polytechnique Fédérale de Lausanne

4 PUBLICATIONS 6 CITATIONS

SEE PROFILE

\section{Ana Paiva}

Instituto Superior Técnico, Inesc-ID

406 PUBLICATIONS $\mathbf{4 , 7 7 4}$ CITATIONS

SEE PROFILE
READS

124
Pedro Sequeira

Northeastern University

24 PUBLICATIONS 163 CITATIONS

SEE PROFILE

Pierre Dillenbourg

École Polytechnique Fédérale de Lausanne 357 PUBLICATIONS 9,816 CITATIONS

SEE PROFILE

Some of the authors of this publication are also working on these related projects:

Project MIOCTI View project

All content following this page was uploaded by Patrícia Alves-Oliveira on 04 September 2016. 


\title{
Children's Peer Assessment and Self-disclosure in the Presence of an Educational Robot
}

\author{
Shruti Chandra, ${ }^{1}$ Patrícia Alves-Oliveira, ${ }^{1}$ Séverin Lemaignan, ${ }^{3}$ \\ Pedro Sequeira, ${ }^{1}$ Ana Paiva, ${ }^{1}$ and Pierre Dillenbourg ${ }^{2}$
}

\begin{abstract}
Research in education has long established how children mutually influence and support each other's learning trajectories, eventually leading to the development and widespread use of learning methods based on peer activities. In order to explore children's learning behavior in the presence of a robotic facilitator during a collaborative writing activity, we investigated how they assess their peers in two specific group learning situations: peer-tutoring and peer-learning. Our scenario comprises of a pair of children performing a collaborative activity involving the act of writing a word/letter on a tactile tablet. In the peer-tutoring condition, one child acts as the teacher and the other as the learner, while in the peer-learning condition, both children are learners without the attribution of any specific role. Our experiment includes 40 children in total (between 6 and 8 years old) over the two conditions, each time in the presence of a robot facilitator. Our results suggest that the peer-tutoring situation leads to significantly more corrective feedback being provided, as well as the children more disposed to self-disclosure to the robot.
\end{abstract}

\section{INTRODUCTION}

Different methods of learning have been explored to foster childhood education and researchers are seeking new approaches to improve them. In designing an educational scenario, robots have been introduced playing diverse roles with children to support learning. Some researchers have used peer-assisted learning methods involving an interaction with robots like peer-tutoring (PT) and peer-learning (PL). For example, Kanda et al., used Robovie, a humanoid robot, as an English peer-tutor for Japanese students [1]. The results of this study showed that the robot could form relationships with children and also encouraged some of them to improve their English. Furthermore, the EMOTE project ${ }^{1}$ aims to address the role of empathy in educational robots, using a multidisciplinary approach [2]. In this project, a robotic tutor with empathetic qualities is used to assist and engage learners in several topics such as sustainability and mapreading [3, 4]. In the same line, the Second Language

\footnotetext{
${ }^{1}$ Shruti Chandra is with the École Polytechnique Fédérale de Lausanne, Switzerland and Instituto Superior Técnico, University of Lisbon, Portugal (phone: +351-214233517; fax: +351-214233290. E-mail: shruti.chandra@tecnico.ulisboa.pt. Patrícia Alves-Oliveira is with INESC-ID and Instituto Universitário de Lisboa (ISCTE-IUL), CIS-IUL, Lisboa, Portugal. E-mail: patricia.alves.oliveira@inesc-id.pt. Pedro Sequeira and Ana Paiva are with INESC-ID and Instituto Superior Técnico, University of Lisbon, Portugal. E-mail: pedro.sequeiralgaips.inesc-id.pt, ana.paiva@inesc-id.pt

${ }^{2}$ Pierre Dillenbourg is with the École Polytechnique Fédérale de Lausanne, Switzerland. E-mail: pierre.dillenbourg@epfl.ch.

${ }^{3}$ Séverin Lemaignan is with the Plymouth University, Plymouth PL4

8AA, UK. E-mail: severin.lemaignan@plymouth.ac.uk

${ }^{1}$ www.emote-project.eu
}

Tutoring using Social Robots (L2TOR) project $^{2}$ aims to design a child-friendly robot, which will be used to teach preschool children a second language by interacting with them in their social and referential world [5].

The work presented in this paper is under the CoWriter project $^{3}$ that addresses the question of how a robot could help children in the acquisition of handwriting skills [6]. In addition, the project also explores different child-robot interaction modes to maximize children's learning gains. Regarding learning-by-teaching, a recent work within this project addressed the subject of children's perceived responsibility towards their peers in the presence of a robot. The scenario involved two children performing a collaborative learning activity with either a human or a robot facilitator. Within the scenario, one child plays a role of a teacher and the other of a learner. The results suggest that the child acting as a teacher feels more responsible towards his/her peer when the facilitator is a robot compared to the human [7].

Moving forward in this direction, the current work aims to provide a contribution in the human-robot interaction (HRI) field by employing both peer-assisted learning methods, i.e. the PT and PL, and comparing children's assessment behavior and their self-disclosure in an educational context. With this purpose, our experiment consists of a betweensubjects design with two conditions: 1) PT condition: a pair of children performs a collaborative learning activity designed according to the PT method; 2) PL condition: the same activity is performed, designed with the $P L$ method. Both conditions were performed in the presence of a robot facilitator whose role was to support the interaction flow between children, in particular by asking them to assess their peer's performance by providing corrective feedback [8]. The study was conducted with 6 to 8 years old children.

Although there has been a plethora of research on the PL and PT methods, less attention has been paid on how these methods can impact children's behavior towards their peers in a learning scenario where a robot is present. In other words, we want to discover whether their peer-assessment behavior is influenced by the role they are assigned to. In addition, we want to explore how peer interactions occurred during these learning methods affect the self-disclosure of children towards the robot.

\footnotetext{
${ }^{2}$ www.12tor.eu

${ }^{3}$ http://chili.epfl.ch/cowriter
} 


\section{RELATED WORK}

\section{A. Educational Theories}

The PL and PT are two forms of peer-assisted learning methods in education; both of these differ in the way they encourage student's interaction and the quality of peer engagement. Usually, the interaction in each of these methods occurs between two students. The PL is a reciprocal learning method in which there is mutual benefit to both students, i.e. they both act as a teacher and as a learner [9]. The reciprocal nature of this method is a key point, as students do not hold power over each other by virtue of their responsibilities or position [10]. Kanda et al. [11] conducted a two-month field study in an elementary school using Robovie robot as a peerlearner/friend. The results revealed that the robot continued interacting with many children and was able to make friendly relations with them.

Contrasting to the PL method, in the PT method there is an unambiguous and consistent distinction between the learning and teaching roles among the students [9]. It also creates an unequal alliance due to the position of responsibility that one student would hold [10]. The PT is often supported on the grounds of the learning-by-teaching method. Research shows that when using this approach, most of the students benefited in some way, and that same-age tutors were as effective as cross-age tutors $[12,13]$. In one of the studies, Tanaka and Matsuzoe [14] used the Nao robot ${ }^{4}$ as a carereceiving interactive agent where children taught the robot English verbs through the learning-by-teaching method. The results of this study suggested that the care-receiving robot enhanced children's spontaneous learning and accelerated their motivation to provide care-taking. Hood et al. [6] also used this method in a scenario where children taught handwriting skills to the Nao robot. The results showed that the robot was able to engage children successfully and improved the children's writing skills.

In this paper, we use the PT and the PL methods as a way to understand how children assess their peers in the presence of a robot during a collaborative writing activity. Moreover, literature defines peer assessment as an integral part of the learning experience for students while performing peerassisted learning methods. Sadler [15] suggested that formative assessment includes both feedback and self-monitoring. According to Hattie et al. [16], "Feedback is powerful in its effect when it is addressed to a learning context and it is most powerful when it addresses faulty interpretations". Furthermore, most effective types of feedback are in the form of cues, reinforcement, evaluation and corrective feedback to learners [17]. Based on these interpretations, in our current work, we used corrective feedback as a peer assessment approach, which is provided by a child and directed towards the faults present in writing (task performance) of another child .

\footnotetext{
${ }^{4}$ Aldebaran robotics: https://www. aldebaran.com/en.
}

\section{B. Self-Disclosure}

Self-disclosure is the act of verbally disclosing personal information about oneself to another, including feeling, thought and experience, and is considered as a key in the growth of close relationships [18, 19]. In the context of the PT method, one of the pedagogical advantages for the tutee is self-disclosure [20]. Furthermore, within HRI some research has examined the self-disclosure behavior of people towards a robot. Mumm et al. [21] found that the people who disliked the robot also disclosed less to it. In this work, we want to explore how the PT and PL methods could influence the selfdisclosure of children to the robot facilitator. In particular, we would like to answer the question: "Is children's selfdisclosure to the robot influenced by the role they play according to the PL and PT methods?"

\section{EXPERIMENTAL HYPOTHESES}

The overall goal of this work concerns the assessment of children's behavior on their peers and their self-disclosure in the presence of a robot facilitator, while performing a collaborative activity. In this context the research questions and the hypothesis of the experiment are:

- Q1: What type of corrective feedback (minimal or extended) would children provide in each condition? Does this feedback differ across the conditions?

We hypothesize that corrective feedback is higher and extensive in the PT condition as one child (tutor), who plays a role of teacher, has an explicit position of responsibility [10]. Therefore, we expect the tutor-child to provide more and extended corrective feedback to the tutee-child compared to the PL condition, where no roles are assigned to children (resulting in a balanced distribution of responsibility and position).

- Q2: Would the self-disclosure by children to the robot facilitator in the PT condition be higher in comparison to the PL condition?

Given the characteristics of the PT method, we hypothesize that self-disclosure by the tutee-child is higher in the PT condition when compared to the PL condition. As shown in past research resorting to the PT method, one of the pedagogical advantages for the tutee is an immediate feedback with corresponding higher selfdisclosure [20].

\section{Methodology}

\section{A. Participants}

The experiment was conducted in "Escola 31 de Janeiro" in Parede, Portugal. 40 Portuguese-speaking children in the age group of 6 to 8 years ( $1^{\text {st }}$ and $2^{\text {nd }}$ grade) participated in the experiment. Only children who assented and whose parents signed the consent form participated in the experiment. The experiment followed the ethical norms of privacy and responsibility of HRI studies [22]. 


\section{B. Material}

The material in the experiment included two tactile tablets with stylus, one for each child, installed with a writing app developed specifically for the experiment. Regarding the writing activity involved in the experiment, we created four colorful cards written with a letter/word as $\mathrm{h}$, Lua ${ }^{5}$ (moon), gelado (ice-cream), and Rainbow. Each of the cards were introduced with an increased difficulty level as provided by the inscribed word length. The last card had the word Rainbow inscribed as it represented the longest and most unfamiliar word (since Portuguese speaking children are not expected to know this English word). For the pre- and posttests we used a sheet with some letters (j, D, K, y, W, t, $\alpha$, and $\pi$ ). The last two letters ( $\alpha$ and $\pi$ ) were included to level the expertise of children (since none of the children are expected to know these Greek letters). In terms of the technical setup, this consisted of 3 video cameras, 2 lavalier microphones and a Nao robot (only torso part). The selection of the material and experimental protocol was finalized with the help of the schoolteachers.

\section{Platform}

A Wizard-of-Oz (WoZ) interface application, named "CoWriterWiz", was developed to control the robot's behavior. A server application, named "CoWriterServer", was also used to manage communications between the tablets in order to visualize and store the drawings of letters and words performed by children during the experiment in realtime. The Nao robot and the WoZ interface application were connected through the high-level integration framework Thalamus [23, 24], which was responsible to accommodating social robots and possibily to including virtual components such as multimedia applications.

The writing app was designed to provide a dual user interactive feature, which displays the shapes being written on one tablet onto the other tablet. The app on each tablet displayed shapes with a different color to distinguish the writings of one child to the other. This interactive capability allowed children to correct each other on their own tablet in real-time. In addition, it also has an eraser button, which a child could use to erase his/her writing.

\section{Conditions}

Condition 1: A robot acts as a learning facilitator and interacts with a pair of children during a collaborative learning activity designed according to the PT method, in which one child plays the role of the teacher, while the other plays the role of the learner.

Condition 2: This condition is similar to Condition 1 but instead of the PT method, the learning activity was designed according to the PL method, meaning that no roles were assigned to the children and therefore both were considered as teachers and learners.

\footnotetext{
${ }^{5}$ As the study was performed in a Portuguese school, Lua and gelado were written in the Portuguese language and Rainbow was written in the English language.
}

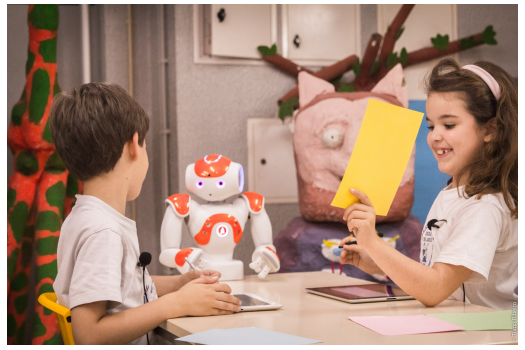

Fig. 1: Children interacting with a robot in PL/PT condition

Each session was performed with a pair of children and a robot according to one of the conditions and lasted about 1520 minutes. Condition 1 (PT condition) was performed with 24 children (12 pairs) and the Condition 2 (PL condition) with 16 children (8 pairs). Due to the ongoing submission of the consent forms during the whole study, we were not able to assure a balanced number of participants in both conditions. Fig. 1 depicts the classroom setup of the study. A WoZ procedure, which is commonly used in HRI [25], was used in which the robot's behavior was remotely-controlled by a human expert referred to as the wizard. In our study, a psychologist acting as the Wizard was present in the classroom where the study took place but hidden from the participants.

\section{E. Protocol}

During the introduction of the experiment, a researcher would explain to the participants that they are going to write some letters on a paper and then on tactile tablet in the presence of a robot. All the participants were informed that if they do not wish to continue the learning activity, they could stop but no participant left during the experiment. The experiment followed these steps:

1) Pre-test: In this phase, a researcher asked the two children to individually copy the given letters (j, D, K, y, $\mathrm{W}, \mathrm{t}, \alpha$ and $\pi$ ) on a paper sheet.

2) Learning activity with the robot: After completing the pre-test, the children were guided to the experiment setup room and were instructed to sit around the table where the robot facilitator was already placed. The researcher explained that they were going to perform a collaborative writing activity on a tablet with the robot. The researcher then left the room, leaving the children solely with the robotic facilitator. The interaction pattern of the learning activity in both conditions of the study progressed as follows:

Welcome greeting: The interaction started with the introduction of the robot and the children. As most of the children had never seen a robot before, this step was important to provide some familiar ground to initiate the interaction.

Tutorial: In the second step, the robot explained the writing activity and the features of the writing app. Next, some time was reserved for the children to draw freely on the tablet to get familiar with the writing app.

Collaborative learning activity: The third step of the interaction pattern was dedicated to the learning activity. First, the robot explained the writing task to the children and assigned roles to them according to the conditions (PT 
or PL). In the PT condition, one child, selected at random, was instructed to play the role of a teacher and the other the role of a learner. For the writing task, four different colored cards with a different letter or word were placed on the table facing down (see Fig. 1). In the PT condition, the robot asked the tutor-child to pick a card and show it to the learner-child so that he/she could write the letter or word on the tablet application. Following the PT method, the learner-child wrote the letters and words on the tablet, while the tutor-child was responsible to provide corrective feedback on the writing performance in whatever ways were possible, e.g. by writing a correction on the tablet, or by verbally expressing it. After the learner-child finished writing such letter/word, the robot prompted the tutor-child to ensure that all corrections were provided. This process was repeated until all four colored cards were picked. Furthermore, the assigned roles of the children were not altered in this condition to make the interaction simpler for them.

In the PL condition, no roles were assigned to the children and the robot alternatively asked one of the children to pick a card. Both were instructed to write a letter/word on the tablet. Following the principles of the reciprocal peer-learning method [9], after writing both children were asked to provide corrective feedback on the other's task performance. Again, the process was repeated for all the four cards. In this condition, although the robot did not explicitly assign any role to the children, implicitly both children behaved as teachers as well as learners.

On every finished card, the robot asked both the children one social question related to the respective word to keep them engaged in the activity. In order to avoid the cases where the children would ask social questions back to the robot, it would always provide its answer regardless of being questioned by the children.

Goodbye greeting: In this last step of interaction, the robot thanked the children for their time.

3) Post-test After finishing the interaction with the robot, children were guided to the same room where they performed the pre-test. The pre-test activity was repeated and thus also served as a post-test.

We noticed that during the tutorial period, most of the children discussed features of the writing app. During the learning activity period, children corrected each other only when the robot prompted them to do so. Sometimes, they asked queries to the robot, related to the ongoing task. Since the robot's behavior was controlled by the researcher, it would repeat the task instructions again.

\section{F. Analysis}

With the purpose of examining the interactions during the experiments, we performed video and audio analysis of all the sessions by coding and annotating the verbal behaviors (corrective feedback, self disclosure) of both children. The annotations were performed with two independent coders using the ELAN multimedia annotation tool ${ }^{6}$. Regarding the

\footnotetext{
${ }^{6}$ https://tla.mpi.nl/tools/tla-tools/elan/
}

TABLE I: Verbal Behaviour.

\begin{tabular}{|c|c|c|}
\hline $\begin{array}{l}\text { Verbal } \\
\text { behaviour }\end{array}$ & Definition & Example \\
\hline $\begin{array}{l}\text { Corrective } \\
\text { Feedback } \\
\text { (minimal) }\end{array}$ & $\begin{array}{l}\text { Minimal response re- } \\
\text { lated to the correc- } \\
\text { tions of the letters and } \\
\text { words. }\end{array}$ & $\begin{array}{l}\text { Robot: Is the shape of } \\
\text { the letter is correct? } \\
\text { tutor-child: Yes }\end{array}$ \\
\hline $\begin{array}{l}\text { Corrective } \\
\text { Feedback } \\
\text { (extended) }\end{array}$ & $\begin{array}{l}\text { Extended response re- } \\
\text { lated to the corrections } \\
\text { of letters and words. }\end{array}$ & $\begin{array}{l}\text { Robot: Is the shape of } \\
\text { the letter is correct? } \\
\text { tutor-child: No, it's not. } \\
\text { This part should be } \\
\text { round. }\end{array}$ \\
\hline $\begin{array}{l}\text { Self Disclosure } \\
\text { (minimal) }\end{array}$ & $\begin{array}{l}\text { Minimal response re- } \\
\text { lated to the social ques- } \\
\text { tions asked by robot. }\end{array}$ & $\begin{array}{l}\text { Robot: What is your } \\
\text { favorite flavor of Ice- } \\
\text { cream? } \\
\text { Child: Chocolate }\end{array}$ \\
\hline $\begin{array}{l}\text { Self Disclosure } \\
\text { (extended) }\end{array}$ & $\begin{array}{l}\text { Extended response } \\
\text { related to the social } \\
\text { questions asked by the } \\
\text { robot. }\end{array}$ & $\begin{array}{l}\text { Robot: What is your } \\
\text { favorite flavor of } \\
\text { Icecream? } \\
\text { Child: Chocolate! I } \\
\text { love it! What is yours? }\end{array}$ \\
\hline
\end{tabular}

reliability of the participant's behavior, the Cohen's kappa showed .92 of agreement for the verbal behaviors and .80 of agreement for the pre-/post-test scores. First, data from the verbal behavior and pre-/post-test scores were tested for normal distribution using the Shapiro-Wilk normality test. The hypothesis that the data comes from a normal distribution was not confirmed, hence we analyzed the data using the non-parametric Exact Wilcoxon rank-sum (MannWhitney U) test which was also appropriate for the unequal sample size data.

\section{Results}

\section{A. Corrective Feedback}

Corrective feedback is the verbal response related to the corrections provided by a child on the performance of another child. Table I presents the types and examples of corrective feedback annotated. The corrective feedback given by children was considered as being either as minimal or extended, according to $[8,26]$. We note that the study was designed in a way that the dynamics between the participants is triadic, but the interaction between the children is dyadic. This means that although children provide corrective feedback as a direct response to the robotic facilitator, the feedback is implicitly directed at the other child but through the robot. In the PT condition, although the tutor-child was responsible to give feedback on the performance of the learner-child, many times during interaction the latter gave feedback regarding the corrections. For annotation purposes, we considered such cases as corrective feedback by the learner-child over his/her own performance.

In order to assess whether the roles assigned to the children have an impact on their assessment behavior in the presence of a robot, we compared the feedback of all children in the PL condition with the tutor-children and also the learner-children (separately) in the PT condition. The result of a Man-Whitney $U$ test suggested that all learner children in the PT condition gave significantly more extended feedback to their peers $(\mathrm{Mdn}=5.0)$ in comparison to the 
(a)

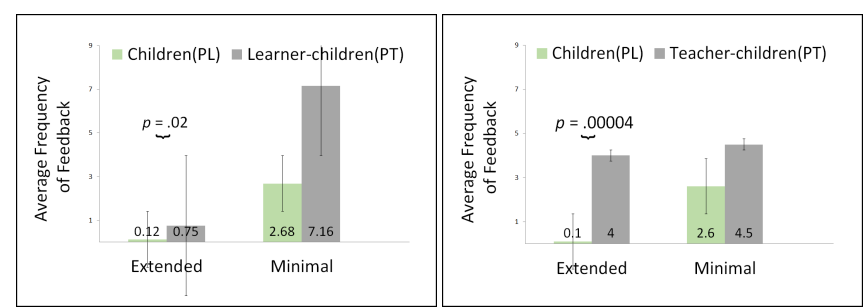

Fig. 2: Results of the corrective feedback between: (a) learner-children in the PT condition $\&$ all children in the PL condition; (b) tutor-children in the PT condition \& all children in the PL condition.

children in the PL condition (Mdn $=0.0), U=57, p<0.05$, $r=.43$, as depicted in Fig. 2(a). On the other hand, the results showed that all tutor-children in the PT condition gave significantly more extended corrective feedback to their peers $(\mathrm{Mdn}=2.5)$ in comparison to the children in the $\mathrm{PL}$ condition $(\mathrm{Mdn}=0.0), U=21, p<.001, r=.73$, as seen in Fig. 2(b). No significant difference was found in minimal corrective feedback provided by children between the two conditions. These results validate our first hypothesis that corrective feedback is higher in the PT condition. Further discussion is provided in Section VI.

\section{B. Self-Disclosure}

During the interaction between the children and the robotfacilitator, children disclosed themselves to the robot when asked several social questions. Again, self-disclosure was evaluated here as minimal or extended (Table I). With the purpose of examining the effect of the two conditions, we compared the self-disclosure of all children in the PL condition with the tutor-children and also the learner-children (separately) in the PT condition. The results showed that all learner-children in the PT condition gave significantly more extended self-disclosure to the robot $(\mathrm{Mdn}=6.5)$ in comparison to the children in the PL condition $(\mathrm{Mdn}=2.0$ ), $U=46.5, p<.05, r=.44$, as illustrated in Fig. 3(a). Also, all tutor-children in the PT condition disclosed significantly more in terms of extended self-disclosure $(\mathrm{Mdn}=6.0)$ in comparison with the children in the PL condition $(\mathrm{Mdn}=$ 2.0), $U=34.5, p<.05, r=.54$, as seen in Fig. 3(b). No significant difference was found in terms of minimal self-disclosure between the two conditions. These results support our second hypothesis, i.e. self-disclosure by children is higher in the PT condition compared to the PL condition.

\section{Learning Gains}

To explore the impact of the two methods on the children's learning involving the interaction with a robot, we compared their pre- and post-test individual scores for each condition. As depicted in Fig. 4(a), the results in the PT condition showed a significant improvement in children's learning gains in the post-test $(\mathrm{Mdn}=15.0)$ as compared to the pretest $(\mathrm{Mdn}=12.0), U=131.5, p<.001, r=.47$. However, no significance difference in pre-/post-test scores was found in the PL condition, as seen in Fig. 4(b).

(a)

(b)

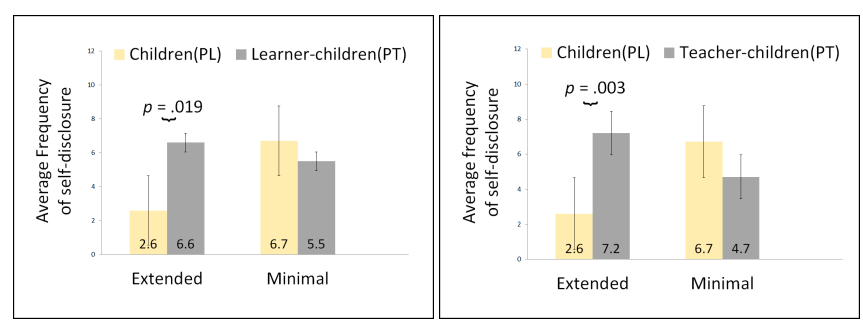

Fig. 3: Results of the self-disclosure between: (a) the learnerchildren in the PT condition \& all children in the PL condition; (b) tutor-children in the PT condition \& all children in the PL condition.

(a)

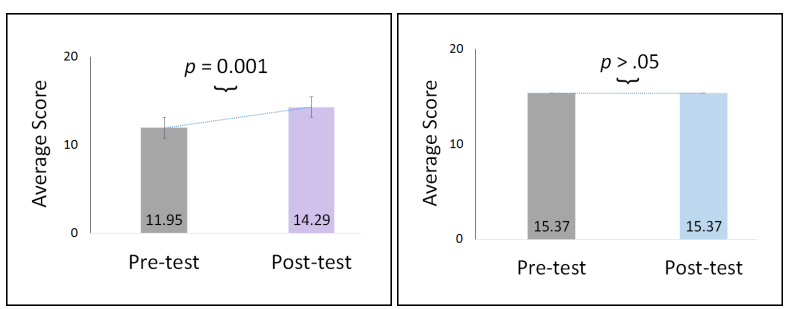

Fig. 4: Results of the pre- \& post-test score of all children in the: (a) PT condition; (b) PL condition

\section{Discussion}

Overall, the results of our study regarding corrective feedback suggest that in the PT condition, children who played a role of teacher gave more extended feedback compared to the children in the PL condition with no assigned role. These results therefore show that the assessment behavior was affected by the role of tutor-child, who had a responsibility to provide feedback (corrections) to the learner-child. In addition, learner-children in the PT condition also provided more extended self-corrective feedback compared to the children in the PL condition. This result suggests that the more corrective feedback they got from the peer-teacher, the more they responded. Furthermore, the relevance of the results lies in the type of feedback provided by the children-both tutor and learner children gave more extended feedback, meaning that they provided more extensive feedback with deepened corrections, which in turn supports the effectiveness of the roles in the PT scenario.

In relation to self-disclosure, our results show that the teacher and learner children in the PT condition disclosed more compared to the children in the PL condition. These results are consistent with findings previously reported in [20]. Nonetheless, the PT method not only benefited the tutee but also the tutor as the tutor-children disclosed more compared to the children in the PL condition. This suggests that selfdisclosure may also depend on the context of the learning scenario - the roles played by the children, depending on the peer-assisted learning method, may elevate their selfdisclosure to the robot.

The results of the PT condition regarding corrective feedback combined with the learning gains are consistent with 
Black \& William [27], who concluded that "the provision of challenging assignments and extensive feedback lead to greater student engagement and higher achievement". Since all children in the PT condition gave more extended feedback compared to the children in the PL condition, this suggests that providing extensive feedback leads to higher post-test scores.

\section{CONClusions \& Future Work}

In this paper we have studied the assessment behavior's of children on their peers by using two peer-assisted learning methods, namely peer-learning and peer-tutoring, in the presence of a robot acting as an interaction facilitator. The results of the experiment suggest that the role played by a child in a peer-tutoring scenario can boost the corrective feedback provided on her peer. We also showed how self-disclosure of children to the robot can vary according to the peer-assisted learning method used. In that regard, our results show that the attribution of roles makes children disclose more information to the robot. These results can help other HRI studies in the design of learning scenarios for children involving the interaction with a robot. The conclusions from our study also poses questions suitable for further investigation, e.g. whether the assessment behavior of children shows the same effects if a robot has a role of a teacher or a learner, or if the role of the robot would affect child's self-disclosure to it? In the future, we plan to address these questions and explore more in this direction by performing long-term studies regarding both conditions.

\section{ACKNOWLEDGMENTS}

This work was supported by national funds through Fundação para a Ciência e a Tecnologia (FCT) with reference UID/CEC/50021/2013. The first and second authors respectively acknowledge grants ref. SFRH/BD/51935/2012 and SFRH/BD/110223/2015, funded by the FCT. P. Sequeira acknowledges a BDP grant from project INSIDE ref. CMUPERI/HCI/0051/2013. The authors show their gratitude to "Escola 31 de Janeiro" in Parede, Portugal and its school principal, teachers and students for their participation and helpful suggestions in this research.

\section{REFERENCES}

[1] T. Kanda, T. Hirano, D. Eaton, and H. Ishiguro, "Interactive robots as social partners and peer tutors for children: A field trial," HumanComputer Interaction, vol. 19, no. 1, pp. 61-84, June 2004.

[2] A. Jones, D. Küster, C. A. Basedow, P. Alves-Oliveira, S. Serholt, H. Hastie, L. J. Corrigan, W. Barendregt, A. Kappas, A. Paiva, et al., "Empathic robotic tutors for personalised learning: A multidisciplinary approach," in Social Robotics. Springer, 2015, pp. 285-295.

[3] P. Sequeira, P. Alves-Oliveira, T. Ribeiro, E. D. Tullio, S. Petisca, F. S. Melo, G. Castellano, and A. Paiva, "Discovering Social Interaction Strategies for Robots from Restricted-Perception Wizard-of-Oz Studies," in Proceedings of the 11th ACM/IEEE Int. Conf. on HumanRobot Interaction (to appear), ser. HRI 2016, 2016.

[4] G. Castellano, A. Paiva, A. Kappas, R. Aylett, H. Hastie, W. Barendregt, F. Nabais, and S. Bull, "Towards empathic virtual and robotic tutors," in Artificial Intelligence in Education, ser. Lecture Notes in Computer Science, H. Lane, K. Yacef, J. Mostow, and P. Pavlik, Eds. Springer Berlin Heidelberg, 2013, vol. 7926, pp. 733-736.

[5] T. Belpaeme, J. Kennedy, P. Baxter, P. Vogt, E. E. Krahmer, S. Kopp, K. Bergmann, P. Leseman, A. C. Küntay, T. Göksun, et al., "L2TORSecond Language Tutoring using Social Robots," in Proceedings of the
International Conference on Social Robotics - WONDER Workshop, 2015

[6] D. Hood, S. Lemaignan, and P. Dillenbourg, "When children teach a robot to write: An autonomous teachable humanoid which uses simulated handwriting," in Proceedings of the Tenth Annual ACM/IEEE Int. Conf. on Human-Robot Interaction. ACM, 2015, pp. 83-90.

[7] S. Chandra, P. Alves-Oliveira, S. Lemaignan, P. Sequeira, A. Paiva, and P. Dillenbourg, "Can a child feel responsible for another in the presence of a robot in a collaborative learning activity?" in Robot and Human Interactive Communication (RO-MAN), 2015 24th IEEE Int. Symposium on. IEEE, 2015, pp. 167-172.

[8] J. Bitchener, "Evidence in support of written corrective feedback," Journal of Second Language Writing, vol. 17, no. 2, pp. $102-118$, 2008.

[9] D. Boud, R. Cohen, and J. Sampson, "Peer learning and assessment," Peer Learning in Higher Education: Learning from \& with Each Other, p. 67, 2001.

[10] M. Keppell, E. Au, A. Ma, and C. Chan, "Peer learning and learningoriented assessment in technology-enhanced environments," Assessment \& Evaluation in Higher Education, vol. 31, no. 4, pp. 453-464, 2006.

[11] T. Kanda, R. Sato, N. Saiwaki, and H. Ishiguro, "A two-month field trial in an elementary school for long-term human-robot interaction," Robotics, IEEE Transactions on, vol. 23, no. 5, pp. 962-971, 2007.

[12] K. J. Topping, Peer assisted learning: A practical guide for teachers. Brookline books, 2001

[13] D. Fuchs, L. S. Fuchs, and P. Burnish, "Peer-assisted learning strategies: An evidence-based practice to promote reading achievement," Learning Disabilities Research \& Practice, vol. 15, no. 2, pp. 85-91, 2005.

[14] F. Tanaka and S. Matsuzoe, "Children teach a care-receiving robot to promote their learning: Field experiments in a classroom for vocabulary learning," Journal of Human-Robot Interaction, vol. 1, no. $1,2012$.

[15] D. R. Sadler, "Formative assessment and the design of instructional systems," Instructional science, vol. 18, no. 2, pp. 119-144, 1989.

[16] J. Hattie and H. Timperley, "The power of feedback," Review of educational research, vol. 77, no. 1, pp. 81-112, 2007.

[17] J. Hattie, "Influences on student learning," Inaugural lecture given on August, vol. 2, p. 1999, 1999.

[18] N. L. Collins and L. C. Miller, "Self-disclosure and liking: a metaanalytic review." Psychological bulletin, vol. 116, no. 3, p. 457, 1994.

[19] K. Dindia, M. Allen, R. Preiss, B. Gayle, and N. Burrell, "Selfdisclosure research: Knowledge through meta-analysis," Interpersonal communication research: Advances through meta-analysis, pp. 169$185,2002$.

[20] K. J. Topping, "The effectiveness of peer tutoring in further and higher education: A typology and review of the literature," Higher education, vol. 32, no. 3, pp. 321-345, 1996.

[21] J. Mumm and B. Mutlu, "Human-robot proxemics: Physical and psychological distancing in human-robot interaction," in Proceedings of the 6th Int. Conf. on Human-robot Interaction, ser. HRI '11. New York, NY, USA: ACM, 2011, pp. 331-338.

[22] L. D. Riek and D. Howard, "A code of ethics for the human-robot interaction profession," Proceedings of We Robot, vol. 2014, 2014.

[23] T. Ribeiro, E. Di Tullio, L. J. Corrigan, A. Jones, F. Papadopoulos, R. Aylett, G. Castellano, and A. Paiva, "Developing interactive embodied characters using the thalamus framework: a collaborative approach," in Intelligent Virtual Agents. Springer, 2014, pp. 364 373.

[24] T. Ribeiro, A. Pereira, E. Di Tullio, P. Alves-Oliveira, and A. Paiva, "From thalamus to skene: High-level behaviour planning and managing for mixed-reality characters," in Proceedings of the IVA 2014 Workshop on Architectures and Standards for IVAs, 2014.

[25] N. Dahlbäck, A. Jönsson, and L. Ahrenberg, "Wizard of oz studies: Why and how," in Proceedings of the 1st Int. Conf. on Intelligent User Interfaces, ser. IUI '93. New York, NY, USA: ACM, 1993, pp. 193-200.

[26] P. H. Kahn Jr, T. Kanda, H. Ishiguro, N. G. Freier, R. L. Severson, B. T. Gill, J. H. Ruckert, and S. Shen, "“robovie, you'll have to go into the closet now": Children's social and moral relationships with a humanoid robot." Developmental psychology, vol. 48, no. 2, p. 303, 2012.

[27] P. Black and D. Wiliam, "Assessment and classroom learning," Assessment in education, vol. 5, no. 1, pp. 7-74, 1998. 